ORIGINAL ARTICLE

\title{
Use of mechanical patient lifts decreased musculoskeletal symptoms and injuries among health care workers
}

\author{
J Li, L Wolf, B Evanoff
}

Injury Prevention 2004;10:212-216. doi: 10.1136/ip.2003.004978

See end of article for authors' affiliations

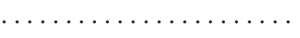

Correspondence to: Dr Bradley A Evanoff, Washington University School of Medicine, $660 \mathrm{~S}$ Euclid Avenue, Campus Box 8005, St Louis, MO 63110, USA; bevanoff@ im.wustl.edu
Objective: To evaluate the effectiveness of mechanical patient lifts in reducing musculoskeletal symptoms, injuries, lost workday injuries, and workers' compensation costs in workers at a community hospital. Design: Pre-post intervention study.

Setting: Three nursing units of a small community hospital.

Patients or subjects: Nursing personnel.

Interventions: Mechanical patient lifts were made available and nursing staff trained in their use between August 2000 and January 2001.

Main outcome measures: Workers completed symptom surveys at baseline and six months after lift training. Pre-intervention and post-intervention rates of injuries and lost workday injuries using Occupational Safety and Health Administration logs of the three study units, from the period July 1999 through March 2003 were analyzed. Injuries potentially related to lifting patients were included in the analyses. Using workers' compensation data from the same time period, the compensation paid (\$ per full time equivalent [FTE]) due to injuries during the pre-intervention and post-intervention period was calculated.

Results: Sixty one staff members were surveyed pre-intervention; 36 (59\%) completed follow up surveys. Statistically significant improvements in musculoskeletal comfort $(p<0.05)$ were reported for all body parts, including shoulders, lower back, and knees. Injury rates decreased post-intervention, with a relative risk (RR) of 0.37 (95\% confidence interval (CI) 0.16 to 0.88 ); decreased injury rates persisted after adjustment for temporal trends in injury rates on non-intervention units of the study hospital ( $R R=0.50$, $95 \% \mathrm{Cl} 0.20$ to 1.26). Adjusted lost day injury rates also decreased ( $R R=0.35,95 \% \mathrm{Cl} 0.10$ to 1.16 ). Annual workers' compensation costs averaged $\$ 484$ per FTE pre-intervention and $\$ 151$ per FTE postintervention.

Conclusion: Reductions were observed in injury rates, lost workday injury rates, workers' compensation costs, and musculoskeletal symptoms after deployment of mechanical patient lifts. Strengths of this study include the community hospital setting and the inclusion of a variety of different outcomes. Limitations include the pre-post study design and the small sample size.
$\mathrm{H}$ ealth care workers experience high rates of work related injuries. These rates are equal to or exceed the injury rates of workers in traditionally high risk occupations. According to data from the Bureau of Labor Statistics for 2001, the national rates of non-fatal injuries and illnesses that required medical treatment or days off work were 8.8/100 full time hospital workers, and 13.5/100 workers in nursing and personal care facilities. As a comparison, the injury rate of construction workers in 2001 was $7.9 / 100$, and $8.1 / 100$ workers in manufacturing. Including only injuries that result in lost workdays, the national rates in 2001 for full time hospital workers was 4.0/100 full time workers, and in nursing homes the rate was 7.3/100 workers. In construction and manufacturing, these rates were 3.9 and 3.6/100 workers. ${ }^{1}$

The majority of injuries incurred by health care workers are musculoskeletal injuries. High rates of musculoskeletal disorders among health care workers, most commonly back injuries and back pain, have been documented in numerous studies. ${ }^{2-4}$ For example, in a British study of nurses leaving the profession permanently, $12 \%$ reported back pain as a main contributory factor. ${ }^{5}$

Musculoskeletal injuries are often the result of the frequent patient lifting and transferring required of health care workers. ${ }^{67}$ One study found that nursing aides were at higher risk for back injuries than nurses, because they perform twice the amount of lifting, bending, and rotation. ${ }^{8}$ In another study, measurements using a biomechanical software program showed that manual patient transfers placed unacceptably high stresses on the low back. Even with two nurses performing the lift, compressive forces at the L5-S1 level far exceeded the upper limit suggested by the National Institute for Occupational Safety and Health. ${ }^{9-12}$

Different interventions to reduce back injuries among health care workers have been studied, including worker education programs, physical conditioning, and ergonomic workplace modifications. Education programs alone have largely been unsuccessful in reducing back injuries or back pain among nurses, ${ }^{13}{ }^{14}$ though a participatory ergonomics program with a training focus was successful among hospital orderlies. ${ }^{15}$ Some physical conditioning programs have been effective, ${ }^{16}{ }^{17}$ but may be difficult to implement extensively due to problems of logistics and employee participation. Interventions which modify job tasks, such as the introduction of lifting teams, have been successful in reducing injuries among nursing personnel. ${ }^{18}$ However, such lifting teams cannot completely eliminate the need for nursing personnel to perform patient handling tasks.

Several recent studies have suggested that mechanical patient lifts can help reduce musculoskeletal injury rates. A

Abbreviations: $\mathrm{Cl}$, confidence interval; $\mathrm{FTE}$, full time equivalent; $\mathrm{OSHA}$, Occupational Safety and Health Administration; RR, relative risk 
study based on a mail survey found that nurses were significantly less likely to have neck or back musculoskeletal disorders when mechanical patient lifts were available in the workplace. ${ }^{19}$ In another study in which a variety of mechanical patient lifts were introduced, significant reductions were seen in the rate of low back injuries in nursing aides and in the average injury associated costs. ${ }^{20}$ A previous study by our group found mechanical patient lifts to be effective in reducing musculoskeletal injury rates in nursing personnel at a group of several hospitals and nursing homes. ${ }^{21}$

This study evaluated the effectiveness of mechanical patient lifts in improving several different outcomes, including musculoskeletal discomfort, rates of injuries, rates of lost workday injuries, and workers' compensation costs. In contrast to most previous studies, the setting was a small community hospital.

\section{METHODS \\ Setting}

This pre-post intervention study took place in three nursing units of a 111 bed community hospital in a suburb of St Louis, Missouri. The three nursing units-medicine/surgery, intensive care unit, and subacute care-were chosen due to the routine manual lifting and transferring of patients performed in these units. Hospital records showed a total of 138 nurses employed in these three units during the year 2000. No mechanical patient lifts had been used in these units before the study.

\section{Intervention}

One portable full body sling lift and two portable stand-up sling lifts ("E-Z Lift" and "E-Z Stand" by EZ Way Inc, Minneapolis, Minnesota) were made available to the three nursing units to enable nursing personnel to lift and transfer patients. The three nursing units were situated on the same floor, with the medicine/surgery unit adjacent to the intensive care unit. These two units shared the full body lift and a stand-up lift. Subacute care was located two hallways away from the other two units and retained one of the stand-up lifts.

The mechanical patient lifts were chosen following guidelines developed in previous laboratory and field research, ${ }^{22}$ and incorporate improvements to overcome barriers to use identified in studies of older equipment. Compared with older lifts, those used in this study are less prone to tipping over, are more maneuverable in tight spaces, are more time efficient than older lifts, require less physical effort for users, and are safer for patients. Friction reducing sheets (Maxislides) were used to position patients in bed in preparation for lift usage. Lift use was recommended for patients weighing over 112 pounds. The full body lifts were recommended for use in patients who were unable to bear at least $25 \%$ of their own weight, while stand-up lifts were recommended for patients who could bear at least $25 \%$ of their own weight, but were still unable to rise from their beds, chairs, or toilets unassisted.

At the start of the intervention period, mechanical patient lifts were made available and one time hands-on training sessions in lift usage were conducted by hospital personnel. All staff directly involved in patient handling, including nurses, nursing assistants, and patient care technicians were expected to attend the training sessions, though we could document participation in training in only $61 \%$ of nursing personnel. The intervention period occurred from August 2000 through January 2001, during which lift usage was tracked, and a lift utilization incentive and retraining program was implemented.

\section{Data collection}

At the training sessions, participants were given baseline ergonomic surveys in which they were asked to rate levels of musculoskeletal comfort of different body parts, the presence and severity of pain, and the levels of physical and mental exhaustion experienced "at the end of a typical work day". Other questions asked participants to provide information on several aspects of their work, such as the degree of support received from their supervisors, the amount of time available to complete tasks, and their level of job satisfaction. Surveys were similar in content to those used in previous studies of health care workers at local institutions. ${ }^{15}$ The surveys were distributed to the same staff after the intervention period, approximately seven months after the baseline surveys.

Injury and lost workday data from July 1999 to March 2003 were obtained from Occupational Safety and Health Administration (OSHA) 200 and 300 logs kept by the hospital. Workers' compensation records from the same time interval were also obtained from hospital administration records. From these records, we ascertained cases of musculoskeletal injuries potentially related to lifting, such as shoulder strains, upper and lower back strains, and knee strains. Injuries that involved exposures to bodily fluids or chemicals, slips, falls, and contusions were not included. By using job titles in the logs, we included only injuries incurred by staff who were directly involved in patient handling. Coders were blinded to the dates on the OSHA logs and workers' compensation records (and thus to pre-intervention or post-intervention status) when extracting these data.

Denominator data used to calculate injury, lost workdays, and cost rates consisted of productive work hour data collected from hospital payroll records. We used the productive work hours of each nursing unit as a whole, as we were unable to obtain work hours of only those staff involved in patient lifting activities. Rates for injury and lost day rates were expressed as injuries or lost days per 100 full time equivalents (FTEs), where l FTE equals 2000 productive hours per year. Workers' compensation rates were expressed as annual dollars per FTE.

To estimate frequency of lift usage, mechanical counters were placed inside the two stand-up lifts to measure frequency of use. These counters recorded each time the mechanical patient lift arm was raised. Counter data were gathered each month during the intervention period. Study personnel also surveyed participating nursing staff monthly as another estimate of the frequency of lift usage.

\section{Statistical methods}

OSHA log and workers' compensation data were entered into Microsoft Excel, and statistical tests and analyses were performed using Excel and SPSS (version 10). For nursing personnel who completed both the baseline and follow up surveys, the Wilcoxon matched pairs signed ranks test was performed to detect differences between symptoms reported pre-intervention and post-intervention. The Mann-Whitney rank sum test was used to detect differences between nursing staff who completed the baseline survey only, and staff who completed both baseline and follow up surveys.

Injury and lost workday rates were compared by calculating the relative risk (RR) and 95\% confidence interval (CI). Before data collection and analysis, we decided to include the six month intervention period (during which lifts were introduced) as part of the pre-intervention period for the purposes of data analysis. Thus, the pre-intervention period ran from July 1999 through January 2001 and included the intervention period (August 2000 to January 2001), while the post-intervention period ran from February 2001 to March 2003. 
Table 1 Musculoskeletal comfort measured by a five point scale* $(n=36)$

\begin{tabular}{llll}
\hline Body part & Mean baseline & Mean 7 months & p Value \\
\hline Neck & 3.2 & 3.6 & 0.013 \\
Shoulders/upper arm & 3.1 & 3.6 & 0.002 \\
Upper back & 2.8 & 3.7 & $<0.001$ \\
Lower back & 2.3 & 3.2 & 0.001 \\
Forearm & 3.8 & 4.3 & 0.032 \\
Wrist/hand & 3.9 & 4.3 & 0.022 \\
Hips/buttocks & 3.3 & 4.0 & $<0.001$ \\
Knees & 3.3 & 4.0 & $<0.001$ \\
Feet/ankles & 2.8 & 3.5 & 0.002 \\
\hline *Five point scale: $1=$ uncomfortable, 5= comfortable. \\
\hline \multicolumn{4}{l}{} \\
\hline
\end{tabular}

\section{RESULTS}

\section{Symptom surveys}

Of a total of 138 health care workers in the three intervention units, $61(44 \%)$ completed the baseline symptom survey in June 2000. The denominator value used is the total number of nursing personnel employed on the intervention units during the year 2000; employee data for the month of June alone were not available. The actual participation rate would therefore be higher than $44 \%$. Of the 61 participants, 36 (59\% of baseline) completed the seven month follow up survey.

Compared with the pre-intervention period, post-intervention surveys showed statistically significant improvements in musculoskeletal comfort levels $(\mathrm{p}<0.05)$ for all nine body parts surveyed (see table 1).

There were no statistically significant pre-post differences in the reported level of physical or mental exhaustion (four point scale), in the severity of pain that interfered with work (three point scale), or in pain medication status (yes/no). However, the nursing staff reported a statistically significant improvement in general health ( 0.2 out of a five point scale, $\mathrm{p}=0.008)$. There was little change in the perceived intensity and difficulty of work, while statistically significant improvements were reported in job satisfaction, willingness to recommend their job to others, and in helpfulness of supervisor (all 0.4 out of a four point scale, $\mathrm{p}<0.05$; see table 2).

In order to assess possible biases due to loss of nonrespondents in the follow up survey, we compared baseline data for persons who did and did not complete the second survey. Cross sectional analysis of the baseline surveys using the Mann-Whitney test showed no statistically significant differences for most survey items. Staff who did not complete a second survey reported greater comfort in three body parts-upper back $(+0.9, \mathrm{p}=0.018)$, lower back $(+0.8$, $\mathrm{p}=0.027)$, and shoulder $(+0.7, \mathrm{p}=0.062)$-than staff who completed follow up surveys. Those surveyed at baseline only reported a lower degree of job satisfaction $(-0.4, p=0.03)$ and were less likely to recommend their job to someone else $(-0.4, p=0.08)$.

\section{Injury, lost workday injury, and workers' \\ compensation rates}

During the study period, 30 injuries potentially associated with lifting were recorded in the OSHA logs, including eight resulting in time lost from work. During the 19 month preintervention period, 18 injuries were recorded, including four with lost time; in the 26 month post-intervention period 12 injuries were recorded, including four with lost time. OSHA recordable injury rates on the intervention units decreased post-intervention from 10.3 injuries per 100 FTE to 3.8 injuries per $100 \mathrm{FTE}(\mathrm{RR}=0.37,95 \% \mathrm{CI} 0.16$ to 0.88$)$. To control for potential temporal trends within the hospital regarding the overall injury rate, the injury rates of all nonintervention units were calculated using the same methods to compare changes during the pre-intervention and postintervention time periods. These data were used to calculate an adjusted RR for the intervention units, assuming a decrease in expected injuries on the intervention units proportional to the decrease seen over time in the nonintervention units, where the RR for injury was 0.74 . The adjusted RR for the intervention units continued to show a post-intervention decline in injury rates $(\mathrm{RR}=0.50,95 \% \mathrm{CI}$ 0.20 to 1.26 ; table 3 ).

RRs for lost workday injuries were calculated and adjusted in the same manner as RR for injuries. Both the crude RR of 0.65 (95\% CI 0.16 to 2.6) and the adjusted RR of 0.35 (95\% CI 0.10 to 1.16 ) showed a decrease in lost workday injury rates. Annual workers' compensation costs for nursing personnel on the intervention units averaged $\$ 484$ per FTE preintervention and \$151 per FTE post-intervention.

\section{Lift counters and compliance surveys}

Lift counter data showed that the stand-up lifts were used the nursing staff, though at less than a desired frequency. Our study team estimated that each stand-up lift should have been used at least 3-4 times per day. Lift counter data showed that each stand-up lift was used an average of 1.1 times per day during the first three months of the intervention; usage fell in the second three months to an average of 0.4 times per day. The stand-up lift shared by the medicine/surgery unit and the intensive care unit was used several-fold more frequently than the stand-up lift in the subacute care unit, possibly because the first lift was being shared by two units, and because patients in the subacute care unit were less incapacitated. On the lift compliance surveys, nursing personnel reported using the lifts occasionally, and reported a number of reasons for not using them, including the increased time required to use the devices and the lack of perceived need to use a mechanical lifting device for many transfers.

\section{DISCUSSION}

We observed beneficial changes in a variety of outcomes after an intervention consisting of deployment of mechanical patient lifts and training in their use. Changes included

Table 2 Psychosocial stressors and job satisfaction $(n=36)$

\begin{tabular}{|c|c|c|c|c|c|}
\hline Survey question & Scale & & Mean baseline & Mean 7 months & p Value \\
\hline Take breaks at work? & $1=$ never & $4=$ always & 2.6 & 2.7 & 0.527 \\
\hline Conflicting demands at work? & $1=$ always & $5=$ none & 1.9 & 2.0 & 0.206 \\
\hline Too little time to do work? & $1=$ too little time & $\begin{array}{l}5=\text { enough } \\
\text { time }\end{array}$ & 1.6 & 1.7 & 0.206 \\
\hline Supervisor helpful? & $1=$ never & $5=$ always & 4.1 & 4.5 & 0.019 \\
\hline Satisfied with job? & $1=$ not at all & $4=$ very & 3.3 & 3.7 & 0.008 \\
\hline Recommend job to others? & $1=$ not strongly & $\begin{array}{l}4=\text { very } \\
\text { strongly }\end{array}$ & 2.8 & 3.2 & $<0.001$ \\
\hline Take job again? & $1=$ not likely & $4=$ very likely & 3.3 & 3.2 & 0.782 \\
\hline
\end{tabular}


Table 3 Injury and lost workday injury rates

\begin{tabular}{lllll}
\hline & $\begin{array}{l}\text { No of injuries } \\
\text { pre-post }\end{array}$ & $\begin{array}{l}\text { No of injuries/100 } \\
\text { FTE pre-post }\end{array}$ & Crude RR (95\% Cl) & Adjusted RR (95\% CI) \\
\hline Injuries & $14 / 8$ & $10.3 / 3.8$ & $0.37(0.16$ to 0.88$)$ & $0.50(0.20$ to 1.26$)$ \\
Lost day injuries & $4 / 4$ & $2.9 / 1.9$ & $0.65(0.16$ to 2.6$)$ & $0.35(0.10$ to 1.16$)$ \\
\hline
\end{tabular}

improvements in musculoskeletal comfort and job satisfaction. Rates of recordable musculoskeletal injuries also decreased substantially post-intervention, as did the lost workday injury rates and workers' compensation costs. Decreases in crude injury rates and lost day rates were statistically significant; after adjustment for temporal trends, large changes persisted but were not statistically significant.

Musculoskeletal comfort data appeared to be a more sensitive indicator of lift effectiveness in our study than did musculoskeletal injury rates. This may have resulted because symptom data were collected at the end of the intervention period, when usage rates of lifts may have been higher than in subsequent months. Also, injury rate data exclude milder lifting related symptoms and minor injuries that do not meet criteria for reporting under federal statutes, and underreporting of injuries on OSHA logs is a widely recognized problem. Symptom survey data have the advantage of providing information directly from participants, and collecting information on milder symptoms that may eventually result in recordable injuries. The results from this study are similar to those of a recent randomized controlled trial of injury prevention performed in a large acute care hospital in Canada, where nursing staff engaging in minimal strenuous lifting reported statistically significant improvements in musculoskeletal symptoms in comparison with the control group. Injury rates, however, were not significantly reduced, possibly reflecting "the less sensitive nature of this indicator compared to subjective indicators". ${ }^{23}$

A unique strength of this study is its setting in a small community hospital. Most other studies of mechanical lifts have been conducted in nursing homes or large acute care hospitals. ${ }^{1921}{ }^{23}$ The community hospital setting of this study provides evidence of mechanical lift effectiveness that is more generalizeable to smaller health care settings. However, this setting led to a limited number of injury cases available for analysis, and made it more difficult to detect statistically meaningful results. Other potential limitations of our study included its pre-post study design and loss to follow up on surveys. Due to the pre-post study design, we cannot be certain that the changes observed on the intervention units resulted from the intervention. To minimize this effect, we controlled for temporal trends in injuries and lost workdays in the hospital as a whole by adjusting injury and lost day injury rates using concurrent data from non-intervention units. For the symptom surveys, staff turnover was a factor for the relatively low survey response rate (59\%). Analyses comparing baseline responses of staff that did and did not complete follow up surveys showed that non-responders were more likely to be dissatisfied with their jobs, consistent with the greater possibility that they would leave their jobs. However, non-responders experienced fewer musculoskeletal symptoms compared with staff that responded to the follow up survey. This decreased the possibility that the absence of non-responders affected reporting of symptoms in a favorable manner.

One problem that we encountered during the study is the reluctance of many nursing staff to use mechanical lifts for patient handling tasks, as seen in the lift counter data. According to the monthly compliance surveys, the main reason reported by staff for not using a mechanical patient

\section{Key points}

- The study evaluated the effectiveness of mechanical patient lifts in reducing the musculoskeletal symptoms and injuries associated with lifting in health care workers.

- The study occurred in a community hospital setting.

- The study showed a decrease in musculoskeletal symptoms, injury rates, and lost day injury rates after implementation of mechanical patient lifts.

- There is a need to develop methods to improve compliance in lift usage to further reduce adverse outcomes.

lift was the lack of perceived need, followed by the lack of time and the lack of maneuvering space. Non-usage and the reasons behind it have been common problems in previous studies involving mechanical patient lifts. ${ }^{1021}$ Staff may be especially unlikely to use lifts for patients in isolation, since each use required that parts of the lift be cleaned or laundered. Inexperience in using the lifts and staff turnover presented other deterrents to compliance. Additional training and incentive programs may be needed before nursing personnel consistently use mechanical lifts. Other means of increasing lift use include encouragement by management, such as the adoption of a policy of no manual lifting. Such policies have been successful in reducing injury rates in long term care facilities. ${ }^{24}$

Despite the low frequency of mechanical lift use and the small size of the study sample, we observed reductions in musculoskeletal symptoms and injury rates. Increased usage of lifts and other aids may result in larger reductions in injury rates. However, changes in work practices and work culture are needed before this technology is fully embraced. Methods of promoting the use of mechanical lifting aids by hospital personnel need to be further developed.

\section{ACKNOWLEDGEMENTS}

The authors wish to acknowledge Ms Barbara Renner, RN, COHN-S, and Mr Kevin Taeckens, whose work was critical to performing the intervention and collecting the data.

\section{Authors' affiliations}

J Li, B Evanoff, Department of Medicine, Washington University School of Medicine, St Louis, Missouri, USA

L Wolf, BJC Health Care, St Louis, Missouri, USA

This study was approved by the Institutional Review Board of Washington University School of Medicine.

\section{REFERENCES}

1 Bureau of Labor Statistics. Survey of occupational injuries and illnesses, 2001. US Department of Labor, 2002.

2 Dehlin O, Hedenrud B, Horal J. Back symptoms in nursing aides in a geriatric hospital. An interview study with special reference to the incidence of low back symptoms. Scand J Rehabil Med 1976;8:47-53. 
3 Estryn-Behar M, Kaminski M, Peigne E. Strenuous working conditions and musculoskeletal disorders among female hospital workers. Int Arch Occup Environ Health 1990;62:47-57.

4 Wilkinson WE, Salazar MK, Uhl JE, et al. Occupational injuries: a study of health care workers at a northwestern health science center and teaching hospital. AAOHN J 1992;40:287-93.

5 Stubbs DA, Buckle PW, Hudson MP, et al. Backing out: nurse wastage associated with back pain. Int J Nurs Stud 1986;23:325-36.

6 Stubbs DA, Buckle PW, Hudson MP, et al. Back pain in the nursing profession: epidemiology and pilot methodology. Ergonomics 1993;26:755-65.

7 Smedley J, Egger P, Cooper C, et al. Prospective cohort study of incident low back pain in nurses. BMJ 1997;314:1225-8.

8 Videman T, Nurminen T, Tola S, et al. Low-back pain in nurses and some loading factors of work. Spine 1984;9:400-4.

9 Ulin SS, Chaffin DB, Patellos CL, et al. A biomechanical analysis of methods used for transferring totally dependent patients. SCI Nurs 1997;14:19-27.

10 Garg A, Owen BD, Carlson B. An ergonomic evaluation of nursing assistants' job in a nursing home. Ergonomics 1992;35:979-95.

11 Gagnon M, Sicard C, Sorois J. Evaluation of forces on the lumbro-sacral joint and assessment of work and energy transfers in nursing aides lifting patients. Ergonomics 1986;29:407.

12 Winkelmolen GHM, Landeweerd JA, Drost MR. An evaluation of patient lifting techniques. Ergonomics 1994;37:921.

13 Feldstein A, Valanis B, Vollmer W, et al. The back injury prevention project pilot study: assessing the effectiveness of back attack, an injury prevention program among nurses, aides, and orderlies. J Occup Med 1993;35: 114-20.
14 Hignett S. Work-related back pain in nurses. J Adv Nurs 1996;23:1238-46.

15 Evanoff B, Bohr P, Wolf $L$. Effects of a participatory ergonomics team among hospital orderlies. Am J Ind Med 1999;35:358-65.

16 Gundewall B, Liliequist $M$, Hansson T. Primary prevention of back symptoms and absence from work: a prospective randomized study among hospitals employees. Spine 1993;18:587-94.

17 Galka ML. Back injury prevention program on a spinal cord injury unit. Sci Nurs 1991;8:48-51.

18 Charney W, Zimmerman K, Walara E. The lifting team: a design method to reduce lost time back injury in nursing. AAOHN J 1991;39:231-4.

19 Trinkoff AM, Brady B, Nielsen K. Workplace prevention and musculoskeletal injuries in nurses. Can J Nurs Adm 2003;33:153-8.

20 Brophy MO, Achimore L, Moore-Dawson J. Reducing incidence of low-back injuries reduces cost. AlHAJ 2001;62:508-11.

21 Evanoff $B$, Wolf $L$, Aton $E$, et al. Reduction in injury rates in nursing personnel through introduction of mechanical lifts in the workplace. Am J Ind Med 2003;44:451-7.

22 Collins JW, Owen BD. NIOSH research initiatives to prevent back injuries to nursing assistants, aides, and orderlies in nursing homes. Am J Ind Med 1996;29:421-4.

23 Yassi A, Cooper JE, Tate RB, et al. A randomized controlled trial to prevent patient lift and transfer injuries of health care workers. Spine 2001;26:1739-46.

24 Collins JW, Wolf $L$, Bell J, et al. An evaluation of a "best practices" musculoskeletal injury prevention program in nursing homes. Inj Prev 2004;10:206-11.

\section{LACUNAE}

\section{Kids busted for walking in street}

Close to 130 schoolchildren from the Illinois's Calumet City appeared before a local hearing officer in May to answer charges of walking in the street. The children-some as young as 9 years-were picked up by Calumet City police officers after school on several occasions during the previous two months. Parents and students alleged the children were taken to the Police Department in squad cars or prisoner vans and detained for up to two hours before being allowed to call their parents.

According to Calumet City code, "where sidewalks are provided, it shall be unlawful for any pedestrian to walk along and upon an adjacent roadway except at a crosswalk". The local law, adopted more than 20 years ago, mirrors the Illinois law on the matter. The enforcement efforts took place in April after the local police chief received numerous complaints from motorists.

Calumet City police estimate there are more than 6000 school age children sent into the city's streets between $2 \mathrm{pm}$ and $3 \mathrm{pm}$ each school day, creating a problem for motorists and a dangerous situation for the kids who walk in the street instead of on the sidewalks. The problem, the police chief said, is when young people walk in the street and defy motorists by refusing to let them pass. Their actions intimidate and frighten motorists and present a danger to the kids, he said (from nwitimes.com, via pednet and Barry Pless).

\section{Why we all love defence lawyers}

A man has been sentenced in a Sydney court for driving offences. From the hearing it appears that the 31 year old man has three previous drink driving convictions, he had had his licence suspended two months ago but was found driving the day before the court hearing. He was facing charges after a near miss with a stationary police car led to the discovery that his car was being driven by his 6 year old nephew in his lap while the man had an alcohol reading of 0.215 -four times the legal limit-not surprising in someone who admitted to having had 26 schooners of beer (equivalent to 17.7 litres) the previous evening. After a guilty plea to charges of having a high blood alcohol content, not wearing a seatbelt, and having an unrestrained child in the car his lawyer argued in mitigation that he was only 250 metres from his sister's home when pulled over by police and had only had three drinks that day. The man was banned from driving for five years, fined US\$1000, and sentenced to six months of weekend detention (from Sydney Morning Herald, April 2004; submitted by Ian Scott). 